\title{
Dietary iron intake in the first 4 months of infancy and the development of type 1 diabetes: a pilot study
}

\author{
Ambika P Ashraf ${ }^{\text {* }}$, Nancy B Eason², Edmond K Kabagambe ${ }^{3}$, Josna Haritha ${ }^{4}$, Sreelatha Meleth ${ }^{5}$, \\ Kenneth L McCormick ${ }^{1}$
}

\begin{abstract}
Aims: To investigate the impact of iron intake on the development of type 1 diabetes (T1DM).

Methods: Case-control study with self-administered questionnaire among families of children with T1DM who were less than 10 years old at the time of the survey and developed diabetes between age 1 and 6 years. Data on the types of infant feeding in the first 4 months of life was collected from parents of children with T1DM $(n=128)$ and controls $(n=67)<10$ years old. Because some cases had sibling controls, we used conditional logistic regression models to analyze the data in two ways. First we performed a case-control analysis of all 128 cases and 67 controls. Next, we performed a case-control analysis restricted to cases $(n=59)$ that had a sibling without diabetes $(n=59)$. Total iron intake was modeled as one standard deviation (SD) increase in iron intake. The SD for iron intake was $540 \mathrm{mg}$ in the total sample and $539 \mathrm{mg}$ in the restricted sample as defined above.

Results: The median (min, max) total iron intake in the first 4 months of life was $1159(50,2399) \mathrm{mg}$ in T1DM cases and $466(50,1224) \mathrm{mg}$ among controls $(P<0.001)$. For each one standard deviation increase in iron intake, the odds ratio $(95 \%$ confidence interval) for type 1 diabetes was $2.01(1.183,3.41)$ among all participants $(128$ cases and 67 controls) while it was $2.26(1.27,4.03)$ in a restricted sample of T1 D cases with a control sibling (59 cases and 59 controls) in models adjusted for birth weight, age at the time of the survey, and birth order.
\end{abstract}

Conclusion: In this pilot study, high iron intake in the first 4 months of infancy is associated with T1DM. Whether iron intake is causal or a marker of another risk factor warrants further investigation.

\section{Background}

The incidence of type 1 diabetes (T1DM) is increasing worldwide and the age of onset is shifting downwards with a significant number of cases occurring between birth and 4 years of age [1-4]. Although the causes for increased incidence and early onset of T1DM are uncertain [1], a number of risk factors associated with induction of autoimmunity in the genetically susceptible individuals have been suggested. These include viral infections (especially enterovirus), stressful life events, vaccinations, early exposure to milk protein, such as bovine insulin, casein and other proteins, early introduction of cereal to infants, low

\footnotetext{
* Correspondence: AAshraf@peds.uab.edu

'Department of Pediatrics/Division of Pediatric Endocrinology and Metabolism, The Children's Hospital, University of Alabama at Birmingham, USA

Full list of author information is available at the end of the article
}

serum vitamin D levels and premature exposure of the gut immune system to foreign proteins [5-19]. The role of environmental determinants in initiating the autoimmunity cascade has also been suggested by studies in discordant/concordant twins [20,21]. Prolonged breast feeding may protect against type 1 diabetes [22,23]. Timing of introduction of solids/cereals was found to influence the risk of developing islet autoimmunity whereas breastfeeding duration/introduction of cow's milk were not statistically associated with the risk factor for developing islet auto antibodies [11,24]. There are no major associations reported between breast feeding and risk of T1DM $[11,25,26]$.

Iron, a major supplement in fortified baby formula, could play a role in modifying the risk for T1DM given that studies in adults have suggested an association 
between iron burden and T2DM. During the first 4 months of life, there is an increased breakdown of fetal erythrocytes leading to increased amounts of circulating iron that are subsequently stored in the parenchymal cells of liver and reticuloendothelial macrophages $[27,28]$. The estimated iron requirement for the term infant for the expansion of the erythrocyte mass and to maintain adequate stores is $1 \mathrm{mg} / \mathrm{kg} /$ day [27,29]. Iron absorption for term infants fed cow's milk formulas varies from $4-12 \%$ depending on a variety of factors including age of the infant, reticulocyte count, body iron status, and composition of the baby formula (e.g., calcium concentration and added ascorbic acid). Absorption levels are even lower with soy milk formula. Studies using isotopically labeled iron reveal that the bioavailability of iron in infant formulas is approximately $11 \%$ [30] and $11.3 \%$ in premature and term babies, respectively [31]. Compared to breast milk, from which approximately $50 \%$ of the iron is absorbed [27,31,32], only about $19 \%$ of the iron in baby formula is absorbed [33]. In vivo, recombinant human lactoferrin added to the infant formula attenuated iron mediated free radical formation and lipid peroxidation [34]. Thus, lack of breast milk lactoferrin may predispose the formula fed infants for further added oxidative damage at critical time period.

The American Academy of Pediatrics Committee on Nutrition recommends early use of iron-fortified formula instead of cow milk [27]. This has reduced the prevalence of anemia in children ages from 6 months to 60 months[35]. Since 1974, the Special Supplemental Nutrition Program for Women, Infants and Children (WIC) provides only high iron formula, unless there are special instructions against this by a health care provider. In 2001 the National Academy of Sciences recommended that the Dietary Reference Intake of iron (DRI) in infants 0-6 months to be $0.27 \mathrm{mg} /$ day with a tolerable upper intake level of $40 \mathrm{mg} /$ day with an assumption that $75 \%$ of iron is from heme iron sources [36]. Mature human breast milk contains $0.5 \mathrm{mg} / \mathrm{L}$ of iron [35], a considerably lower concentration of iron than iron-fortified baby formulas which also vary in the type and source of protein (e.g., bovine, soy or protein hydrolysate). The aim of this study is to explore whether the amount of iron consumed in the first 4 months of life is associated with T1DM before 6 years of age. A 6 year age cut off was used mainly because children are exposed to more environmental stimuli after that age. Even though a cause-effect relationship cannot be validated with this study, we aimed to assess a potential association between iron consumption in the first 4 months of life and risk of developing T1DM as a preliminary step for future studies.

\section{Materials and methods \\ Subjects}

This was a case-control study among children diagnosed with T1DM before the age of six and who at the time of recruitment were not older than 10 years and were receiving care from the pediatric diabetes clinic at the Birmingham Children's Hospital, a University of Alabama at Birmingham (UAB) affiliated hospital. Patients were identified through the Children's Hospital electronic medical records system using ICD 9 diagnosis codes 250.01, 250.03 and 250.13. Surveys were sent to a total of 250 children diagnosed with T1DM before 6 years of age and at the time of survey not $>10$ years old. A total of 141 surveys from children with T1DM were returned of which 130 children with diabetes were entered in the analysis and 11 excluded because of unclear answers. Some $(n=75)$ of the control questionnaires were rejected due to ambiguity in the answers leaving 83 controls eligible for further analysis. Thus our main sample consisted of a total of 130 T1DM cases and 83 controls which includes siblings of T1DM cases. Since type 1 diabetes is characterized by significant insulinopenia which requires insulin administration to control blood sugar, the controls were selected based on parents history of whether or not the sibling had diabetes. Siblings of T1DM children were included in the study if they were aged between 6 years and 10 years of age.

\section{Methods}

After obtaining approval by the University of Alabama at Birmingham Institutional Review Board, 250 questionnaire surveys were mailed out between June 2006 and April 2007. Data collection: A questionnaire and letter of introduction stating that this research is being conducted to determine whether maternal nutrition, childhood infections, co-morbidities and the type and components of infant formula (e.g., minerals and vitamins) are associated with T1DM were mailed to the parents or guardians of the study participants. A questionnaire, which was completed by the parent or caretaker, was used to assess maternal medical history and baby feeding practices (e.g., gestational diabetes, maternal T1DM or type 2 diabetes (T2DM), period of exclusive breast feeding, introduction of supplementary infant formula, type of formula consumed in the first 4 months of life, number of weeks on formula, and vitamins and iron supplements) as well as child specific information such as birth weight, year of birth and illnesses in the first 4 months of life. The names of the patients and their caregivers were not included on the survey form. Anonymous filled questionnaires were returned to the Children's Hospital in self-addressed stamped return 
envelopes (without participants return addresses) provided by the researchers.

\section{Assessment of amount and duration of intake of specific iron containing foods}

The infant formulas were then classified as high or low iron formula based on the self-reported formula brand name. The majority of available products at the time of the study were high iron except Similac low iron ${ }^{\circ}$, Similac PM $60 / 40^{\circ}$ and Enfamil Lipil low iron infant formulas. Comparisons were made between children with T1DM and non-diabetic siblings based on consumption of high-iron, low-iron formulas and breast milk.

If a survey was marked as formula fed for a month, we used a 30 day month. Calculation of total amount of formula ingested was based on normal caloric needs of food intake for infants [37]. Breast milk has $0.5 \mathrm{mg} / \mathrm{L}$ of iron, equivalent to $0.075 \mathrm{mg}$ in $5 \mathrm{oz}$ [35]. "High" iron formula has $12 \mathrm{mg} / \mathrm{L}(1.8 \mathrm{mg} / 5 \mathrm{oz})$ of iron and "low" iron formula has $4.6 \mathrm{mg} / \mathrm{L}(0.7 \mathrm{mg} / 5 \mathrm{oz})$ of formula of ferrous iron. Table 1 depicts the expected amount of iron ingested based on the recommended daily intake of formula or breast milk in the first 4 months of life.

\section{Inclusion and exclusion criteria}

We excluded individuals where the parent could not recall the type of infant nutrition source and whether or not solid foods (e.g., cereals) were introduced before 4 months of age, if there were serious illnesses prior to the diagnosis of diabetes (to exclude medication-induced diabetes), if gestational length was $\leq 37$ weeks) and if diabetes was diagnosed after 6 years of age. Siblings were excluded from the study if they were $>10$ years at the study point for age- matching with the cases.

\section{Statistical analyses}

Data management and analysis was done in Microsoft EXCEL $^{\circ}$ and Statistical Analysis System (SAS version 9.2, SAS Institute Inc., Cary, NC). From total sample of 213, we excluded individuals who had missing data on age $(\mathrm{n}=16)$, sibling rank $(\mathrm{n}=1)$ and one child who iron intake was implausible $(11,988 \mathrm{mg})$. Thus we had 195 children (67 controls and 128 cases) for the main analyses. For subgroup analyses, we created a subset of 59 controls and 59 cases where case had a control sibling. The distribution of iron intake and other continuous variables was checked for normality and log- or square root-transformed where appropriate to improve normality before comparing cases and controls. Because transformations did not completely correct the skewed nature of the data, we used the Wilcoxon Rank Sum test to test for the significance of differences in iron intake as well in other variables between cases and controls. Multivariable conditional logistic regression was performed to test whether the intake of iron is associated with T1DM before and after adjusting for birth weight, age at the time of the survey and birth order. In the final sample, there were two few mother's with a history of gestational diabetes or T2DM $(<4 \%)$. Thus these variables were not included in the multivariate conditional logistic analyses. The results are reported as odds ratios (OR) and 95\% confidence intervals (CI) for $1 \mathrm{SD}$ increase in iron intake for all sources. Associations were considered significant at a $P$-value of 0.05 .

\section{Results}

The mean $( \pm$ SD) age at the time of diagnosis of T1DM was $3.23 \pm 1.32$ years. All study participants were born between 1996 and 2006. The general characteristics of the study population by case-control status are shown in Table 2. There was no association between sibling rank and T1DM, nor was there an association between maternal history of gestational diabetes or T2 D and T1DM in children.

The median duration of breast feeding was significantly higher $(P<0.05)$ in controls $(12$ weeks $)$ than in T1DM cases ( 4 weeks). The median ( $\min , \max )$ total iron intake in the first 4 months of life was 1159 (50, 2399) $\mathrm{mg}$ in T1DM cases and $466(50,1224) \mathrm{mg}$ among controls $(P<0.001)$. The SD for iron intake was $540 \mathrm{mg}$ in the total sample and $539 \mathrm{mg}$ in the restricted sample. Table 3 depicts odds ratios for the association between

Table 1 The amount of iron intake that a normal term infant receiving the recommend daily allowance (RDA) of formula or breast milk would receive in the United States*

\begin{tabular}{lcccc}
\hline Month & $\begin{array}{c}\text { RDA milk } \\
\text { (oz/day) }\end{array}$ & & Iron, mg/day & Vitamin with iron (10 mg/serving) \\
\cline { 3 - 5 } & & High-iron formula & $\begin{array}{c}\text { Low-iron } \\
\text { formula }\end{array}$ & Breast milk \\
\hline First month & 23 & 8.28 & 3.22 & 0.345 \\
Second month & 29 & 10.44 & 4.06 & 0.435 \\
Third month & 29 & 10.44 & 4.06 & 0.435 \\
Fourth month & 30 & 10.8 & 4.2 & 300 \\
\hline
\end{tabular}

* Breast milk has $0.5 \mathrm{mg} / \mathrm{L}$ of iron, equivalent to $0.074 \mathrm{mg}$ in $5 \mathrm{oz}$ [35]. High iron formula has $1.8 \mathrm{mg} / 5 \mathrm{oz}$ of formula and low iron formula has $0.7 \mathrm{mg} / 5 \mathrm{oz}$ of formula. 
Table 2 characteristics of the study participants by diabetes status*

\begin{tabular}{|c|c|c|c|c|c|}
\hline \multirow[b]{2}{*}{ Variable } & \multicolumn{2}{|c|}{$\begin{array}{l}\text { Controls } \\
(n=67)\end{array}$} & \multicolumn{2}{|c|}{$\begin{array}{l}\text { Type } 1 \text { diabetes cases } \\
(\mathrm{n}=128)\end{array}$} & \multirow[b]{2}{*}{$P$} \\
\hline & Median & Min, Max & Median & Min, Max & \\
\hline Age at diagnosis, y & - & - & 3.0 & $0.16,6.0$ & - \\
\hline Age at recruitment, y & 5.0 & $0.4,10.0$ & 6.0 & $2.0,10.0$ & 0.05 \\
\hline Birth weight, kg & 3.32 & $2.3,4.7$ & 3.32 & $1.11,4.91$ & 0.94 \\
\hline Total iron: form., suppl. \& breast milk, mg & 466 & 50,1224 & 1159 & 50,2399 & $<0.0001$ \\
\hline Iron from formula \& supplements, mg & 466 & 0,1213 & 1144 & 0,2399 & $<0.0001$ \\
\hline Duration of feeding low-iron formula, wks & 12 & 0,16 & 0 & 0,16 & $<0.0001$ \\
\hline Duration of feeding high-iron formula, wks & 12 & 0,32 & 10 & 0,16 & 0.10 \\
\hline Duration of breast feeding, wks & 12 & 0,16 & 4 & 0,16 & 0.001 \\
\hline Mother had gestational diabetes, $\%$ & 0 & & 3 & & 0.30 \\
\hline Mother has diabetes, $\%$ & 3 & & 4 & & 1.00 \\
\hline \multicolumn{6}{|l|}{ Sibling rank, \% } \\
\hline First & 42 & & 49 & & 0.44 \\
\hline Second & 49 & & 42 & & \\
\hline Third & 6 & & 8 & & \\
\hline Forth or higher & 3 & & 1 & & \\
\hline
\end{tabular}

* Values are medians, minimum, maximum or percentages.

$+P$ values are from the Wilcoxon rank sum test for continuous variables and from the Fisher's exact test for categorical variables.

$1 \mathrm{SD}$ increase in total iron intake from all sources in first four months of life and type 1 diabetes. For each one standard deviation increase in iron intake, the odds ratio (95\% confidence interval) for type 1 diabetes was $2.01(1.183,3.41)$ among all participants (128 cases and 67 controls) while it was $2.26(1.27,4.03)$ in a restricted sample of T1 D cases with a control sibling (59 cases and 59 controls) in models adjusted for birth weight, age at the time of the survey and birth order. In multivariate analyses, only age at the recruitment was associated with T1DM. For each one year increase in age, the odds ratio for T1DM was $1.44(1.07,1.95)$ in models adjusted for total iron intake, birth weight and sibling rank.

\section{Discussion}

The novel proposition of a causal link between the quantity of iron intake in the first 4 months of life and future development of T1DM is plausible considering the known strong association between ferritin and Type 2 diabetes in adults [38,39], a disorder sometimes diagnostically indistinct from T1DM with similar surrogate autoimmune markers and medical histories. Because in genetically susceptible subjects $\beta$-cell auto antibodies may materialize in infancy [40], this observation buttresses the argument that the environmental trigger for diabetes autoimmunity occurs early in life.

The physiological anemia of infancy seen in the first 2-3 months of life is not due to iron deficiency and does not respond to iron supplementation [35]. A normal term infant has sufficient iron stores for the first 4-6 months of life. Hence, the introduction of iron fortified formula in the critical period of 4-6 months could be potentially baneful. There has been a significant reduction in the prevalence of iron deficiency anemia in 6 to 60 month-old children after the introduction of ironfortified baby formulas. However, there is limited clinical evidence which can be adduced to support the early

Table 3 Odds ratios $(95 \% \mathrm{Cl})$ for the association between total iron intake in first four months of life and type 1 diabetes

\begin{tabular}{lcr}
\hline & Odds ratios (95\% Cl) for $\mathbf{1}$ SD increase in iron intake* \\
\hline Total iron intake, SD unitst & $\begin{array}{c}\text { All participants } \\
\text { (128 cases and 67 controls) }\end{array}$ & $\begin{array}{c}\text { Restricted to cases with a control sibling } \\
\text { (59 cases and 59 controls) }\end{array}$ \\
Age at recruitment, y & $2.01(1.183,3.41)$ & $1.26(1.27,4.03)$ \\
Birth weight, $\mathrm{kg}$ & $1.44(1.07,1.95)$ & $0.77(0.24,2.51)$ \\
Sibling rank & $1.09(0.37,3.27)$ & $2.17(0.77,6.08)$ \\
\hline
\end{tabular}

* Odds ratios are from conditional logistic regression models in which the 4 continuous variables were modeled simultaneously.

† Total iron intake from formula, supplements and breast milk. In the total sample $(n=195)$ one SD unit was 540 mg while it was 539 mg in the restricted sample $(n=118)$. 
introduction of iron fortified formulas in the first 4 months of life.

Although the mechanism remains unresolved, numerous studies have confirmed that prolonged breast feeding protects against T1DM [23], and breast feeding activists advocate the postponement of formula feeding. As regards to iron intake with breast feeding, even though $50 \%$ of the iron is absorbed, which is incontestably a high proportion when compared with cow's milk or iron fortified formula, breast milk per unit volume contains roughly $1 / 10^{\text {th }}$ of the iron content of the "low" iron formulas $[27,32,33,35]$. The net result is that breast fed babies absorb quantitatively far less iron than formula-fed babies, and this fact alone may explain the putative effect of breast milk.

Another confounding variable is that breast fed babies may delay feeding formula, cow's milk, cereals or other solid foods. This practice may avert exposure of the infant to foreign food antigens, such as gluten and bovine insulin, which may induce a cross-reacting immune response, particularly if gut permeability is altered by microbial infection [41]. Contrary to other studies [35], our study did not show that the number of weeks of breast milk ingestion conferred protection, most likely due to the small sample size in our study. Moreover, only a minority of children were on low-iron formula and the majority of children who had low total iron intake in the first 4 months had at some point also received breast milk. The absence of statistically significant association between the number of weeks of breast milk intake and having diabetes in our study is not enough to abandon the tenet that breast feeding is a protective factor against T1DM.

Type 1 diabetes involves the inexorable destruction of $\beta$ cells secondary to autoimmunity. In iron overload conditions such as hemochromatosis, there is excessive iron storage in solid organs and selective destruction of $\beta$ cells. Iron overload form hereditary hemochromatosis is associated with diabetes and impaired glucose tolerance and decreased insulin secretory capacity, which is reportedly reversed with phlebotomy therapy $[42,43]$. Excess pancreatic $\beta$-cells iron reportedly impairs mitochondrial function and glucose-stimulated insulin secretion $[43,44]$.

The etiology of T1DM is likely multifactorial with a complex interplay between genetic, autoimmune, environmental, infectious and dietary factors. The role of iron in the infant formula in manifestation of T1DM was explored in this study. We could not find any studies examining relationship of iron status before onset of T1DM in genetically susceptible individuals. However, as in other autoimmune disorders, there are reports suggesting iron status may play a role in manifestation of systemic lupus erythematosis in murine models [45]. Iron is involved in the proliferation of $\mathrm{T}$ cells and other cells of immune system [46]. Similarly, ferritin reportedly has immune regulatory roles as well [47]. The pathoetiology by which fortified iron formulas could predispose to development of autoimmune diabetes in genetically susceptible individuals is uncertain. Whether the development of T1DM appertains to the actual quantity of iron ingested or is somehow attributable to the type of the fortified iron (ferrous sulfate vs. ferrous fumarate), or duration and timing of iron intake is likewise unclear. Excess cellular uptake of ferrous iron could in theory initiate a oxidation cascade which overwhelms the numerous intracellular protective anti-oxidation biochemical strategies [48]. It is thereby conceivable that the oxidative stress from immoderate iron exposure in the first 4 months in genetically susceptible infants may promote autoimmunity due to overproduction of free radical oxidative species. Parenthetically, ferrous fumarate is thought to produce minimal or no oxidative stress in vitro compared with ferrous sulfate [34]. And, interestingly, lactoferrin in breast milk reportedly attenuates iron-induced oxidative damage in vitro[34]. Finally, in the gut an overabundance of iron may modify the gastrointestinal immune response or its micronutrient milieu [49]. In conclusion, large-scale prospective studies are warranted to determine whether low iron or lactoferrin enriched formulas forefend against T1DM in high risk individuals.

\section{Limitations of the study}

The major methodological pitfall of this retrospective study is that the data are self-reported. Hence, there is a potential chance of error insofar as this information relies on maternal dietary recall over a long duration. A memory bias may exist between that of the child with diabetes and non- diabetic sibling and that could have caused differential misclassification. Even though the letter accompanied the survey did not specify our hypothesis on iron content of formula, it mentioned we are investigating a link between T1DM and any of the minerals, vitamins, infant formulas or maternal nutrition. As the surveys were anonymous we do not have any data (clinical, demographic or medical) about the non-responders. We have excluded all ambiguous surveys. The choice of infant formula after birth depends on parental preferences, cost, co-morbid conditions like colic, acid reflux disease, lactose intolerance, milk protein allergy, type of formula the mother is first exposed too, etc. Consequently, the choice of low iron formula could be a proxy for socioeconomic characteristics or other factors which were not assessed in the surveys. Another confounding factor is that early introduction of bovine milk formula, besides increasing iron intake, may introduce previously proposed diabetogenic protein antigens. 


\section{Conclusion}

This pilot study suggests that higher intake of iron in the first 4 months of life is a probable risk factor for future development of T1DM. These results are not conclusive as this study was not designed to assess risk for T1DM. Even though the association of "high iron intake" with T1DM is seen in this study, in view of potential biases that may have confounded the results of this study, a future prospective large scale study to assess the possible association between high dietary intake of iron in infancy and T1DM is warranted. Whether iron intake is causal or a marker of another risk factor needs to be further investigated.

\section{Acknowledgements}

We are grateful to all families of children with diabetes for completing their questionnaires, without whose help this would have been impossible.

\section{Author details}

'Department of Pediatrics/Division of Pediatric Endocrinology and Metabolism, The Children's Hospital, University of Alabama at Birmingham, USA. ${ }^{2}$ Alabama A \& M University, USA (at the time of study. ${ }^{3}$ The Department of Epidemiology, University of Alabama at Birmingham, USA. ${ }^{4} \cup A B$ school of Medicine, University of Alabama at Birmingham, USA. ${ }^{5}$ The Division of Preventive Medicine, University of Alabama at Birmingham, Alabama, USA.

\section{Authors' contributions}

AA contributed to the study conception, design, data interpretation, drafting and revising the manuscript. NBE conceived the study, participated in the design, data collection and analysis. EKK contributed to statistical analysis, interpretation, and revising the manuscript critically for important intellectual content. JH contributed to study design, study coordination, data collection and organization. SM involved in statistical analysis, interpretation and drafting of the manuscript. KM involved in the study conception, design, and critical revising of the manuscript for important intellectual content. All authors read and approved the final manuscript.

\section{Competing interests}

The authors declare that they have no competing interests.

Received: 25 February 2010 Accepted: 20 September 2010 Published: 20 September 2010

\section{References}

1. Harjutsalo V, Sjoberg L, Tuomilehto J: Time trends in the incidence of type 1 diabetes in Finnish children: a cohort study. Lancet 2008, 371:1777-1782.

2. Variation and trends in incidence of childhood diabetes in Europe. EURODIAB ACE Study Group. Lancet 2000, 355:873-876.

3. Karvonen M, Viik-Kajander M, Moltchanova E, Libman I, LaPorte R, Tuomilehto J: Incidence of childhood type 1 diabetes worldwide. Diabetes Mondiale (DiaMond) Project Group. Diabetes Care 2000, 23:1516-1526.

4. Vehik K, Hamman RF, Lezotte D, Norris JM, Klingensmith G, Bloch C Rewers M, Dabelea D: Increasing incidence of type 1 diabetes in 0 - to 17year-old Colorado youth. Diabetes Care 2007, 30:503-509.

5. Hypponen E, Kenward MG, Virtanen SM, Piitulainen A, Virta-Autio P, Tuomilehto J, Knip M, Akerblom HK: Infant feeding, early weight gain, and risk of type 1 diabetes. Childhood Diabetes in Finland (DiMe) Study Group. Diabetes Care 1999, 22:1961-1965.

6. Peng H, Hagopian W: Environmental factors in the development of Type 1 diabetes. Rev Endocr Metab Disord 2006, 7:149-162.
7. Verge CF, Howard NJ, Irwig L, Simpson JM, Mackerras D, Silink M: Environmental factors in childhood IDDM. A population-based, casecontrol study. Diabetes Care 1994, 17:1381-1389.

8. Siemiatycki J, Colle E, Campbell S, Dewar RA, Belmonte MM: Case-control study of IDDM. Diabetes Care 1989, 12:209-216.

9. Thorsdottir I, Birgisdottir BE, Johannsdottir IM, Harris DP, Hill J, Steingrimsdottir $L$, Thorsson AV: Different beta-casein fractions in Icelandic versus Scandinavian cow's milk may influence diabetogenicity of cow's milk in infancy and explain low incidence of insulin-dependent diabetes mellitus in Iceland. Pediatrics 2000, 106:719-724.

10. Blom L, Nystrom L, Dahlquist G: The Swedish childhood diabetes study. Vaccinations and infections as risk determinants for diabetes in childhood. Diabetologia 1991, 34:176-181.

11. Ziegler AG, Schmid S, Huber D, Hummel M, Bonifacio E: Early infant feeding and risk of developing type 1 diabetes-associated autoantibodies. Jama 2003, 290:1721-1728.

12. Strotmeyer ES, Yang Z, LaPorte RE, Chang YF, Steenkiste AR, Pietropaolo M, Nucci AM, Shen S, Wang L, Wang B, Dorman JS: Infant diet and type 1 diabetes in China. Diabetes Res Clin Pract 2004, 65:283-292.

13. Wahlberg J, Vaarala O, Ludvigsson J: Dietary risk factors for the emergence of type 1 diabetes-related autoantibodies in 21/2 year-old Swedish children. Br J Nutr 2006, 95:603-608.

14. Paronen J, Knip M, Savilahti E, Virtanen SM, Ilonen J, Akerblom HK, Vaarala O: Effect of cow's milk exposure and maternal type 1 diabetes on cellular and humoral immunization to dietary insulin in infants at genetic risk for type 1 diabetes. Finnish Trial to Reduce IDDM in the Genetically at Risk Study Group. Diabetes 2000, 49:1657-1665.

15. Borch-Johnsen K, Joner G, Mandrup-Poulsen T, Christy M, ZachauChristiansen B, Kastrup K, Nerup J: Relation between breast-feeding and incidence rates of insulin-dependent diabetes mellitus. A hypothesis. Lancet 1984, 2:1083-1086.

16. Gimeno SG, de Souza JM: IDDM and milk consumption. A case-control study in Sao Paulo, Brazil. Diabetes Care 1997, 20:1256-1260.

17. Perez-Bravo F, Carrasco E, Gutierrez-Lopez MD, Martinez MT, Lopez G, de los Rios MG: Genetic predisposition and environmental factors leading to the development of insulin-dependent diabetes mellitus in Chilean children. J Mol Med 1996, 74:105-109.

18. Gerstein HC: Cow's milk exposure and type I diabetes mellitus. A critical overview of the clinical literature. Diabetes Care 1994, 17:13-19.

19. Virtanen $S M$, Knip M: Nutritional risk predictors of beta cell autoimmunity and type 1 diabetes at a young age. Am J Clin Nutr 2003, 78:1053-1067.

20. Kaprio J, Tuomilehto J, Koskenvuo M, Romanov K, Reunanen A, Eriksson J, Stengard J, Kesaniemi YA: Concordance for type 1 (insulin-dependent) and type 2 (non-insulin-dependent) diabetes mellitus in a populationbased cohort of twins in Finland. Diabetologia 1992, 35:1060-1067.

21. Hyttinen V, Kaprio J, Kinnunen L, Koskenvuo M, Tuomilehto J: Genetic liability of type 1 diabetes and the onset age among 22,650 young Finnish twin pairs: a nationwide follow-up study. Diabetes 2003, 52:1052-1055.

22. Mayer EJ, Hamman RF, Gay EC, Lezotte DC, Savitz DA, Klingensmith GJ: Reduced risk of IDDM among breast-fed children. The Colorado IDDM Registry. Diabetes 1988, 37:1625-1632.

23. Sadauskaite-Kuehne V, Ludvigsson J, Padaiga Z, Jasinskiene E, Samuelsson U: Longer breastfeeding is an independent protective factor against development of type 1 diabetes mellitus in childhood. Diabetes Metab Res Rev 2004, 20:150-157.

24. Norris JM, Scott FW: A meta-analysis of infant diet and insulin-dependent diabetes mellitus: do biases play a role? Epidemiology 1996, 7:87-92.

25. Hummel M, Fuchtenbusch M, Schenker M, Ziegler AG: No major association of breast-feeding, vaccinations, and childhood viral diseases with early islet autoimmunity in the German BABYDIAB Study. Diabetes Care 2000, 23:969-974.

26. Couper JJ, Steele C, Beresford S, Powell T, McCaul K, Pollard A, Gellert S, Tait B, Harrison LC, Colman PG: Lack of association between duration of breast-feeding or introduction of cow's milk and development of islet autoimmunity. Diabetes 1999, 48:2145-2149.

27. Iron fortification of infant formulas. American Academy of Pediatrics. Committee on Nutrition. Pediatrics 1999, 104:119-123. 
28. Andrews NC: Disorders of iron metabolism. N Engl J Med 1999, 341:1986-1995.

29. Iron balance and requirements in infancy. Pediatrics 1969, 43:134-142.

30. McDonald MC, Abrams SA, Schanler RJ: Iron absorption and red blood cell incorporation in premature infants fed an iron-fortified infant formula. Pediatr Res 1998, 44:507-511.

31. Stekel A, Olivares M, Pizarro F, Chadud P, Lopez I, Amar M: Absorption of fortification iron from milk formulas in infants. Am J Clin Nutr 1986, 43:917-922.

32. Saarinen UM, Siimes MA: Iron absorption from infant milk formula and the optimal level of iron supplementation. Acta Paediatr Scand 1977, 66:719-722.

33. Hertrampf E, Olivares M, Pizarro F, Walter T: High absorption of fortification iron from current infant formulas. J Pediatr Gastroenterol Nutr 1998, 27:425-430.

34. Raghuveer TS, McGuire EM, Martin SM, Wagner BA, Rebouche CJ, Buettner GR, Widness JA: Lactoferrin in the preterm infants' diet attenuates iron-induced oxidation products. Pediatr Res 2002, 52:964-972.

35. Wu AC, Lesperance L, Bernstein H: Screening for iron deficiency. Pediatr Rev 2002, 23:171-178.

36. Trumbo $P$, Yates AA, Schlicker $S$, Poos M: Dietary reference intakes: vitamin $A$, vitamin $K$, arsenic, boron, chromium, copper, iodine, iron, manganese, molybdenum, nickel, silicon, vanadium, and zinc. J Am Diet Assoc 2001, 101:294-301.

37. Jeannette Brakhane Endres RR, Cynthia G: Mense, Food, Nutrition, and the Young Child Prentice Hall, 52003.

38. Jiang R, Manson JE, Meigs JB, Ma J, Rifai N, Hu FB: Body iron stores in relation to risk of type 2 diabetes in apparently healthy women. Jama 2004, 291:711-717.

39. Forouhi NG, Harding AH, Allison M, Sandhu MS, Welch A, Luben R, Bingham S, Khaw KT, Wareham NJ: Elevated serum ferritin levels predict new-onset type 2 diabetes: results from the EPIC-Norfolk prospective study. Diabetologia 2007, 50:949-956.

40. Kimpimaki T, Kupila A, Hamalainen AM, Kukko M, Kulmala P, Savola K, Simell T, Keskinen P, llonen J, Simell O, Knip M: The first signs of beta-cell autoimmunity appear in infancy in genetically susceptible children from the general population: the Finnish Type 1 Diabetes Prediction and Prevention Study. J Clin Endocrinol Metab 2001, 86:4782-4788.

41. Faria $\mathrm{AM}$, Weiner $\mathrm{HL}$ : Oral tolerance: therapeutic implications for autoimmune diseases. Clin Dev Immunol 2006, 13:143-157.

42. Abraham D, Rogers J, Gault P, Kushner JP, McClain DA: Increased insulin secretory capacity but decreased insulin sensitivity after correction of iron overload by phlebotomy in hereditary haemochromatosis. Diabetologia 2006, 49:2546-2551.

43. McClain DA, Abraham D, Rogers J, Brady R, Gault P, Ajioka R, Kushner JP: High prevalence of abnormal glucose homeostasis secondary to decreased insulin secretion in individuals with hereditary haemochromatosis. Diabetologia 2006, 49:1661-1669.

44. Cooksey RC, Jouihan HA, Ajioka RS, Hazel MW, Jones DL, Kushner JP, McClain DA: Oxidative stress, beta-cell apoptosis, and decreased insulin secretory capacity in mouse models of hemochromatosis. Endocrinology 2004, 145:5305-5312.

45. Leiter LM, Reuhl KR, Racis SP Jr, Sherman AR: Iron status alters murine systemic lupus erythematosus. J Nutr 1995, 125:474-484

46. Bowlus CL: The role of iron in T cell development and autoimmunity. Autoimmun Rev 2003, 2:73-78.

47. Recalcati S, Invernizzi P, Arosio P, Cairo G: New functions for an iron storage protein: the role of ferritin in immunity and autoimmunity. J Autoimmun 2008, 30:84-89.

48. Qian SY, Buettner GR: Iron and dioxygen chemistry is an important route to initiation of biological free radical oxidations: an electron paramagnetic resonance spin trapping study. Free Radic Biol Med 1999, 26:1447-1456.

49. Markel TA, Crisostomo PR, Wang M, Herring CM, Meldrum KK, Lillemoe KD, Meldrum DR: The struggle for iron: gastrointestinal microbes modulate the host immune response during infection. J Leukoc Biol 2007, 81:393-400.

doi:10.1186/1758-5996-2-58

Cite this article as: Ashraf et al: Dietary iron intake in the first 4 months of infancy and the development of type 1 diabetes: a pilot study. Diabetology \& Metabolic Syndrome 2010 2:58.

\section{Submit your next manuscript to BioMed Central and take full advantage of:}

- Convenient online submission

- Thorough peer review

- No space constraints or color figure charges

- Immediate publication on acceptance

- Inclusion in PubMed, CAS, Scopus and Google Scholar

- Research which is freely available for redistribution 